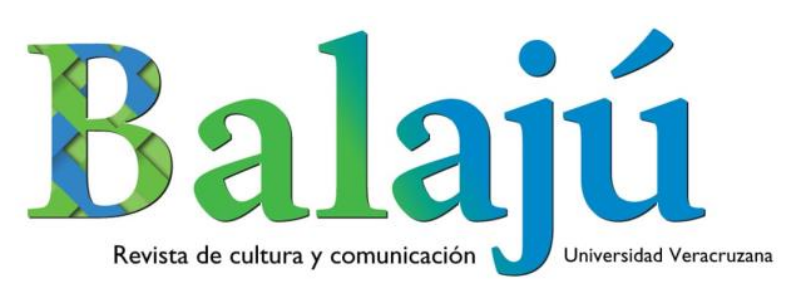

ISSN2448-4954

No. 10, Año 6

Enero- Julio 2019

https://doi.org/10.25009/blj.voi10.2568

\title{
Intelectuales indígenas y memoria histórica: el caso de la bandera Siera en Zongolica, Veracruz \\ Indigenous Intellectuals and Historical Memory: The Route of the Siera Flag in Zongolica, Veracruz
}

\section{Claudia Morales Carbajal ${ }^{1}$}

https://orcid.org/oooo-ooo2-3881-1170

\section{Carlos Alberto Casas Mendoza ${ }^{2}$}

https://orcid.org/oooo-0002-5557-7742

RESUMEN: Este artículo analiza un ritual cívico denominado el recorrido de la bandera Siera. En este ritual se (re)producen símbolos identitarios que materializan las aspiraciones regionales de un grupo de pobladores de la Sierra de Zongolica, Veracruz. El principal foco alrededor del que giran estos rituales recupera la Independencia de México como acto fundacional del nacionalismo mexicano y del lugar que los zongoliqueños elaboran en la producción de su memoria histórica. Analizamos el papel de los diferentes grupos de intelectuales regionales -en este caso, maestros normalistas- en la construcción de una identidad indígena autónoma, que pueda vincularse de manera resignificada a la

\footnotetext{
1 Universidad Veracruzana, México. Correo electrónico: claucarv@yahoo.com.mx

2 Universidad Veracruzana, México. Correo electrónico: casasmendoz@hotmail.com Fecha de recepción: 23/10/2018. Aceptado: 19/08/2019
} 
identidad nacional. El texto muestra cómo este acto conmemorativo se desenvuelve dentro de un proceso continuo de disputa y de negociación.

PALABRAS CLAVE: Intelectuales, indígenas, memoria, rituales cívicos, nahuas.

ABSTRACT: This article describes a civic ritual called the Route of the Siera Flag. In this ritual, a group of local intellectuals (re)produces symbols of identity that embody the regional aspirations of a group of people from the Sierra de Zongolica, Veracruz. The ritual revolves around the recuperation of Mexican Independence as a founding act of Mexican nationalism and also site of production of zongoliqueño historical memory. We analyze the role of different groups of regional intellectuals -in this case, teachers- in the construction of an autonomous indigenous identity that may be linked in a re-signified way to national identity, and show how this commemorative act unfolds within a continuous process of dispute and negotiation.

KEYWORDS: Intellectuals, indigenous peoples, memory, civic rituals, nahuas. 


\section{Intelectuales indígenas y memoria histórica: el caso de la bandera Siera en Zongolica, Veracruz}

\section{Introducción: rememorando historia y (re)construyendo símbolos}

Este artículo analiza el ritual cívico que cada 15 de septiembre tiene lugar en varios municipios de la Sierra de Zongolica para conmemorar la participación de la ciudad en la lucha independentista. El principal foco de estas celebraciones es una serie de actos públicos que son conocidos regionalmente con el nombre de El recorrido de la bandera Siera. Argumentamos que, detrás de la escenificación de estos actos cívicos, se despliega toda una parafernalia ritual que se propone configurar la memoria histórica del pueblo de Zongolica a través de un proceso de "tradición selectiva" (Williams, 1980). En las conmemoraciones se retoman episodios de la historia regional, vinculándolos a un evento fundacional central para el nacionalismo mexicano: la guerra de Independencia. Estos acontecimientos están simbólicamente representados en una bandera proclamada como precursora del actual lábaro patrio-, el símbolo más importante del nacionalismo mexicano.

El ritual cívico de la bandera Siera, más allá de su aparente originalidad, muestra a escala de la micropolítica local (Gledhill, 2000), una de las vertientes del proceso actual de reelaboración de identidades culturales y su relación con el Estado-nacional. En este artículo se centra la atención en los diferentes actores sociales que han participado en esta ceremonia, desde su origen, en 1989, hasta 2010, así como en el contenido histórico y simbólico del ritual mismo. Enfocamos el papel que las comunidades de intelectuales locales, indígenas y no indígenas, han tenido 
en la construcción de la identidad regional y la forma en que la cultura popular se convierte en un elemento de disputa entre los diferentes grupos que componen el campo político.

En particular, nos interesa destacar el papel que los maestros normalistas tienen en la región como actores clave, para entender cómo se elaboró y se difundió un tipo de nacionalismo basado en la reinterpretación de símbolos y de mitos (Gutiérrez, 2012). Los maestros a nivel regional jugaron un papel muy relevante en este proceso. Su conocimiento de la historia nacional y de la importancia de la memoria y la identidad en el contexto nacional los hizo conscientes de la situación de marginalidad de sus comunidades y, a la vez, los dotó de las herramientas para construir, a través de la recuperación de la memoria histórica de sus poblaciones, una identidad autónoma que les permitió negociar su posición dentro del contexto local y regional.

Las discusiones sobre los procesos de construcción del nacionalismo deben ser analizadas dando seguimiento a la relación que las regiones mantienen con el Estado-nacional (Lomnitz, 1995). Estos procesos no son homogéneos, por más que exista toda una narrativa que intenta estandarizarlos. Se encuentran intervenidos por procesos en los que las culturas regionales juegan un papel central. Así, por ejemplo, el nacionalismo que emanó de Morelos y de la Huasteca Potosina mantiene lógicas y ordenamientos políticos diferenciados, en función de los procesos de negociación y de legitimación que sus grupos regionales mantuvieron con el Estado-nacional, tal como lo demuestra Claudio Lomnitz (1995).

La elaboración de rituales cívicos y de actos conmemorativos adquiere señalada relevancia en la construcción de la legitimidad, tanto en el ámbito nacional como en el regional. Es a través de estos actos que se expresan las imágenes y las figuras del nacionalismo. Los dramas políticos 
son inseparables de la representación de lo político en las sociedades modernas (Abélès, 1988: 391). Hay una tendencia a desestimar el papel que lo ritual tiene en las sociedades contemporáneas, cuando es a través de las acciones rituales que las figuras e imágenes del poder son elaboradas.

En especial, las narrativas sobre lo nacional mantienen una fuerte densidad de simbolismos y de usos de la memoria histórica, para fijar la posición que cada grupo tiene en el campo político. En algunos casos constituyen verdades fuentes de resitencia local frente a los procesos de hegemonización de los Estados-nacionales (Rappaport, 1990). Estas narrativas están sujetas a las coyunturas y temporalidades históricas, no son campos cerrados. Así, un mismo acto conmemorativo, como el de la Independencia, puede tener múltiples escenarios de transposición simbólica y de reelaboración pública, de acuerdo con los contextos históricos que se estén negociando en cada momento (Casas, 2016).

En este artículo nos interesa mirar lo nacional y su construcción, desde la perspectiva del tejido fino de los ámbitos locales. Es en estos contextos (locales y regionales) donde se negocian las figuras y las imágenes diferenciadas del nacionalismo. El debate sobre lo que está adentro y lo que queda fuera de lo nacional evidencia la lucha entre las narrativas de hegemonía y las de resistencia. Es un verdadero debate sobre el pasado, las identidades, las políticas de la memoria y la forma en cómo lo nacional se construye desde múltiples lugares, no solo desde las narrativas del Estado (Romero, 2001).

La Bandera Siera se ha convertido, para los habitantes de Zongolica, en un símbolo de identidad que les permite situarse dentro de la historia nacional. La Sierra de Zongolica, habitada en su mayoría por población nahua, es representada de manera marginal y periférica por los habitantes mestizos de los valles centrales del estado de Veracruz, región que limita 
con ellos. En este sentido, el recorrido de la bandera, que abarca tanto las altas montañas como las partes bajas de los valles, cobra un especial significado simbólico y territorial. El artículo se centra en los juegos simbólicos y en los desplazamientos que los rituales cívicos evocan. Tomaremos como punto de referencia las celebraciones étnicas registradas en 2010, para de allí trazar los distintos momentos históricos por los que ha transitado la celebración. Nuestro argumento central coloca a los intermediarios políticos como artífices y figuras clave de estos procesos.

\section{El ritual cívico, una aproximación etnográfica e histórica}

El 15 de septiembre de 2010, cuando empezaron a despuntar los primeros rayos del sol de una mañana fría, un grupo mayormente de hombres y con algunas mujeres jóvenes, se reunió en la plaza de la ciudad de Zongolica para iniciar un largo recorrido en bicicleta. El trayecto partió de la ciudad de Zongolica y, ascendiendo por las Cumbres de Acultzingo, llegó hasta Tehuacán, Puebla, para retornar por el mismo camino. Se trató de una carrera de relevos que tocó varias de las ciudades que se localizan en esta ruta. Además del contingente juvenil, participaron el presidente de Zongolica, algunos de los síndicos y secretarios de su gabinete y el cronista de la ciudad, el maestro Honorio Contreras Pavia. El motivo de este recorrido fue llevar la bandera Siera -símbolo de la participación del pueblo de Zongolica en la independencia de México- a las ciudades por las que esta pasó entre 1810 y 1812.3 Esta ceremonia se viene repitiendo año con año desde 1989. Sin embargo, en 2010 fue especialmente significativo, ya que se

3 Existen dudas entre los historiadores en cuanto al año en que Zongolica se unió al movimiento de independencia. Véanse Cruz (2011: 528) y Ortiz (1997: 215). 
conmemoraba el bicentenario de la independencia de México y los cien años de la fundación de la ciudad.

Durante el recorrido, el primer homenaje a la bandera Siera fue en la ciudad de Tehuacán. Allí fue recibida por el alcalde y por un grupo de miembros del gobierno local, acompañados por bandas de guerra de varias escuelas. El Palacio Municipal hizo las veces de escenario y tuvo como telón de fondo a grupos de jóvenes estudiantes y a las referidas bandas de guerra escolares. El acto inició con palabras de bienvenida a la bandera, así como un discurso por parte de los miembros del ayuntamiento de Zongolica, en el que se narró la historia del lábaro y la del poblado serrano.

La ciudad anfitriona recibió la insignia tricolor que portaban los jóvenes deportistas y le rindió homenaje. Al finalizar el acto, el presidente de Zongolica entregó al de Tehuacán una réplica de la bandera. En respuesta, la ciudad anfitriona agradeció la distinción y prometió guardarle los honores merecidos. Enseguida los jóvenes deportistas tomaron la bandera e iniciaron la carrera de relevos hacia la ciudad de Acultzingo, próxima estación en el recorrido (Figura 1). En general, el acto cívico fue similar en cada una de las ciudades. Las variaciones se relacionaron con el número de participantes y lo lucido de los discursos. El itinerario incluyó, en orden de visita, las ciudades de Acultzingo, Maltrata, Ciudad Mendoza, Huiloapan, Nogales, Río Blanco, Orizaba, Rafael Delgado, Tlilapan, San Andrés Tenejapan, Tequila, Los Reyes y, el destino final, la ciudad de Zongolica. La elección de estas ciudades obedece a que ellas fueron visitadas por el "Ejército de la Sierra" durante la lucha independentista, aunque algunos de los cronistas locales insisten en que faltaría incorporar algunas ciudades más como Coscomatepec y Huatusco. 
Figura 1. Jóvenes portando la bandera Siera en Río Blanco, Veracruz.

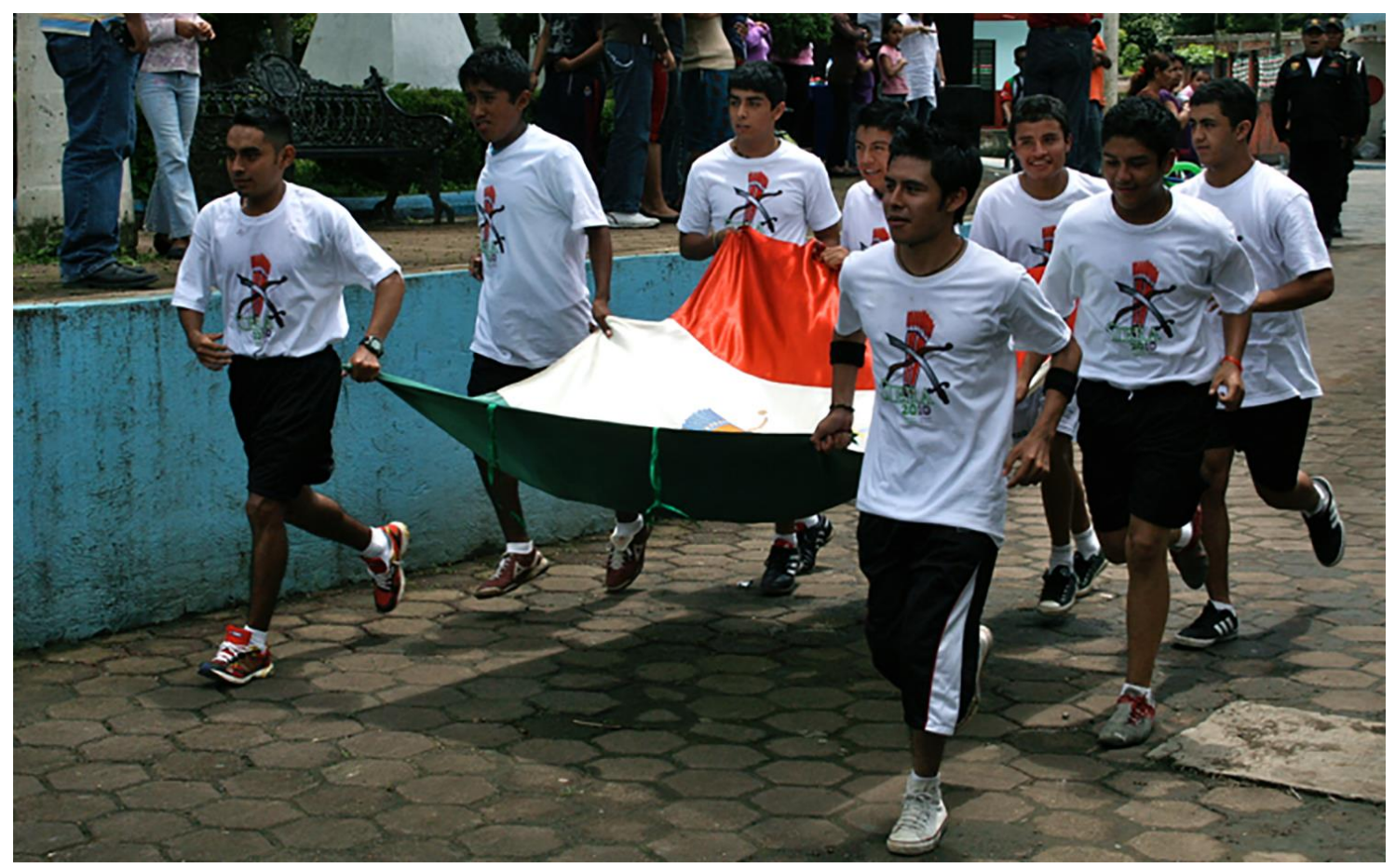

Foto: Claudia Morales Carbajal

Los discursos, aunque no iguales en todos los municipios, narraban la participación heroica del pueblo de Zongolica -simbolizada en la bandera Siera-, durante la guerra de independencia de México. También hacían referencia al héroe local, el cura Juan Moctezuma Cortés, al que se le atribuye la elaboración de la bandera y el liderazgo del grupo insurgente.

El cura Juan Moctezuma Cortés, originario de Tepeji de la Seda, Puebla, fue de noble linaje, emparentado con la real casa del emperador Moctezuma II (Cruz, 2011: 522-526). Durante la guerra de independencia, el clérigo se convirtió en la cabeza de una de las ramificaciones que José 
María Morelos articuló en las regiones serranas para lograr la desestabilización de los grupos realistas localizados en las metrópolis. Junto con el cura Mariano de la Fuente y el licenciado Rafael Argüelles, Juan Moctezuma colaboró con Morelos en la toma de la ciudad de Orizaba y en el asalto de varias haciendas de la región, así como en el decomiso de una importante cantidad de tabaco, cuya venta fue empleada para cubrir los gastos del movimiento, entre los que se encontraba acuñar monedas (Ortiz, 1997: 55-59).

La bandera Siera fue elaborada por los miembros del "Ejército de la Sierra" durante el movimiento revolucionario encabezado por Juan Moctezuma. Tiene los mismos colores y la disposición de la bandera mexicana actual, solo que, en lugar del águila devorando la serpiente, presenta en su franja central un carcaj con flechas cruzado por una espada y un arco. Su denominación, según Carolina Baur (2010), se deriva de la modificación de la expresión 'sierra', la cual, al ser trasladada al náhuatl, se convierte en 'Siera'. El estandarte los acompañó durante varias de las batallas y asaltos que se realizaron en la región.

En 1921, después de la entrada del Ejército Trigarante a la Ciudad de México, los alzados regresaron a las montañas y uno de los sobrevivientes, Manuel de la Cruz Tello, mantuvo en su poder el pabellón tricolor que había sido portado en las batallas, ahora manchado con sangre y horadado por las balas. La bandera permaneció en poder de la familia de Manuel de la Cruz por generaciones, y durante esos años ellos le rindieron culto en sencillas ceremonias privadas. En 1918, el diputado Samuel Tello, descendiente de Manuel de la Cruz, donó el lábaro al Museo Nacional de Historia -ubicado en el Castillo de Chapultepec- junto con algunos papeles históricos relacionados con su origen (Figura 2). 
Figura 2. La bandera Siera original en la Suprema Corte de Justicia, Ciudad de México, después de una conferencia referida a ella.

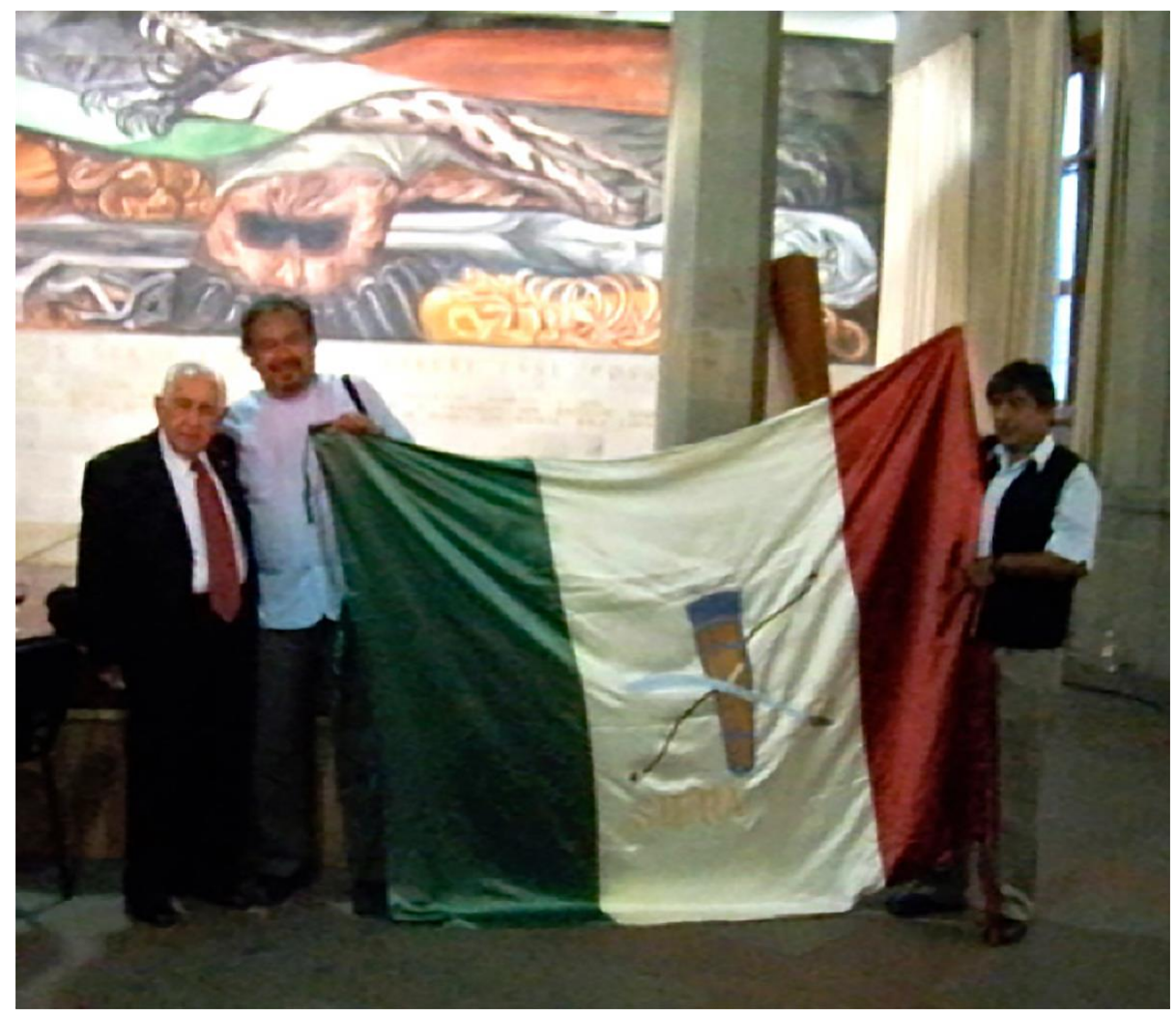

Fuente: http://zongolica.net/sanchez.html.

Al parecer la entrega no tuvo el impacto que el diputado esperaba, pues fue guardada y olvidada por varios años, hasta que la investigadora Carolina Baur Arenas se interesó en su historia y se dio a la tarea de reunir datos en cuanto a su origen e importancia.4 De su investigación se desprende que la bandera Siera es una de las precursoras del actual lábaro patrio, quizá el

4 Carolina Baur Arenas (1903-1987) fue una reconocida maestra normalista y luchadora por los derechos de los niños y de las mujeres, acreedora de numerosos premios y reconocimientos a nivel nacional e internacional. 
antecedente más antiguo, anterior a la bandera que se elaboró en Iguala y que durante tiempo era considerada como el primer ejemplar. Su elaboración, según los estudios realizados a las fibras con que fue manufacturada, ocurrió entre 1812 y 1817. El escudo que se presenta en su centro es muy parecido al que exhibían las monedas que se acuñaron en Zongolica por el movimiento independiente, en ese mismo año (Baur, 2010).

El actual homenaje que se le rinde a la bandera fue promovido en 1989 por un grupo de pobladores, profesores en su mayoría, que conformaban la casa de cultura de Zongolica. Estos ciudadanos propusieron hacer una cabalgata de la ciudad de Zongolica a Orizaba. Las cabalgatas han sido un recurso de escenificación simbólica utilizado en la Huasteca. Los gobernadores de los estados de San Luis Potosí, Veracruz, Tamaulipas e Hidalgo organizaban un desfile hacia distintos puntos de su territorio, en un afán por definir y hermanar una región. La acción de avanzar hacia distintas comunidades de la región simbolizaba la apropiación de los estados de su territorio interior. En el caso del recorrido de la bandera Siera, la configuración simbólica operaría en sentido contrario: una localidad avanza fuera de sus límites municipales para "delimitar" y "apropiarse" de una región simbólica.

Posteriormente, el evento devino en una carrera deportiva y se extendió en un recorrido que incluía catorce ciudades, iniciando en Zongolica y terminando en Tehuacán, Puebla. El propósito de este programa fue dar a conocer a las poblaciones vecinas la participación de la sierra en la lucha por la independencia, así como elevar la bandera Siera a insignia regional.

De manera paulatina, el gobierno municipal fue cobrando un lugar especial dentro de la celebración. En primera instancia fue solo un invitado 
más; posteriormente, empezó a aportar recursos económicos para el evento. Finalmente, las autoridades locales se apropiaron definitivamente de la ceremonia, incorporándola a la agenda de las celebraciones del municipio, dándole el carácter de oficial y relegando a los iniciadores del acto al papel de espectadores. En 2010, las autoridades ya detentaban completamente la organización y el desarrollo del recorrido. Los pobladores que iniciaron el ritual habían sido sustituidos en la planeación y en la ejecución de la ceremonia. En este año doblemente conmemorativo, un grupo de maestros, entre ellos el cronista de la ciudad Honorio Contreras P., participó en la oratoria y en la dirección de la ceremonia.

Los maestros, aun de forma individual -pues no es posible hablar de un movimiento que los congregue como unidad--, han tenido una actuación relevante en la transformación social y política de la Sierra de Zongolica. Para entender su papel en la ceremonia, es necesario remitirnos a las condiciones particulares de su entorno, en especial al momento histórico en que se formaron como maestros normalistas y a elementos particulares de sus biografías y de las labores culturales que han desarrollado.

\section{Los maestros como intermediarios culturales}

La sierra de Zongolica es un conjunto de elevaciones que se encuentra en el límite entre los actuales estados de Puebla, Oaxaca y Veracruz. 5 Es uno de los tres bastiones de población nahua que existen en el estado de Veracruz. Según el Programa de las Naciones Unidas para el Desarrollo (PNUD), actualmente se ubica entre las regiones más marginadas del país. Algunos

5 La sierra se encuentra limitada al norte y al noroeste por el valle de Acultzingo y Orizaba; al norte y al noreste, por la planicie costera; al sur, por el estado de Oaxaca y al este y sureste, por el valle de El Palmar-Tezonapa. 
de los municipios que la componen, como Tehuipango y Mixtla de Altamirano, se encuentran entre los de más bajo índice de desarrollo y alta mortandad infantil a nivel nacional (PNUD, 2012). Este dato resulta contrastante con el desarrollo económico de la región ya que, desde la Colonia, en estas tierras han prosperado dos de los cultígenos más importantes para el estado: el tabaco, que se cultivó en esta región desde 1765 hasta principios del siglo xx, y el café, que continúa siendo uno de los productos más importantes del mercado veracruzano. La producción de estas industrias creó, desde la Colonia, un crecimiento diferencial en la región, merced a la distinción de una zona cálida favorable a los cultivos y una zona fría que se convirtió en exportadora de mano de obra para las haciendas y las fincas.

Los municipios de Tequila y Zongolica son los que tienen un mayor grado de urbanización y en los que se han concentrado, desde la fundación de las primeras villas, los comercios y los centros educativos más importantes. El municipio de Zongolica contaba en 2017 con 44587 habitantes; de este total, 38017 son considerados indígenas (INEGI, 2017).

Históricamente la ciudad de Zongolica ha sido el principal centro económico de la región. También fue más favorecida, en cuanto al desarrollo educativo, en comparación con el resto de la sierra. La primera escuela cantonal empezó a funcionar en 1887, dos años después de que el gobierno de Veracruz decretara la creación de escuelas primarias en la cabecera de cada cantón. Esta escuela fundadora se llamó General Ignacio Zaragoza.

Uno de los primeros directores de esta institución fue el profesor Melitón Guzmán i Romero, quien registró las experiencias de su paso por la sierra en un libro. A la fecha, esta obra titulada El ex Cantón de Zongolica (1968) es clave para entender el contexto histórico y social en que se 
implementó el modelo educativo nacional en las montañas, a principios del siglo Xx. El maestro Melitón narra algunas de las principales dificultades para ejercer la profesión, que iniciaban con la necesidad de los profesores de dejar sus ciudades de origen para asentarse en las montañas. En esta primera etapa, todos los maestros venían de fuera y tenían que emplear varios días para trasladarse hasta Zongolica, ya que todavía no se contaba con un sistema carretero. El trayecto desde la ciudad de Orizaba, donde se encontraba una Escuela Normal, semillero natural de los profesores de la sierra, implicaba más de un día.

El maestro Guzmán trabajó en Zongolica de 1906 a 1914. En este tiempo implementó numerosos cursos y talleres, como los de actuación y contabilidad; también creó un internado para alumnos indígenas. Él afirmaba que una de las principales dificultades del proceso educativo en la sierra era llevar la educación no solo a las ciudades urbanizadas como Zongolica, sino también a las comunidades de difícil acceso. Consideraba su labor como educador de manera similar a un apostolado: "Pasé gratos años entregado a la regeneración de la raza tan abatida por el abandono i el vicio; pero para quienes asoman ya los albores de la educación redentora" (Guzmán, 1968: 22).

Al finalizar la revolución hubo un interés muy grande por llevar la educación a toda la población. La ideología nacionalista, especialmente en la forma de mitos fundacionales, símbolos como la bandera y rituales, se transmitió a través de la educación primaria. Para llegar a los rincones más apartados se recurrió a las escuelas rurales, creadas en 1911 como centros dependientes de las escuelas primarias urbanas. La zona serrana presentaba dificultades por la escasez de maestros. Los normalistas, recién egresados, optaban por quedarse a trabajar en los centros urbanos, por lo que hubo el propósito de dar un mayor impulso a las escuelas rurales. 
En Zongolica, la presencia de un grupo de maestros que se definiera como tal y que tuviera incidencia dentro de la comunidad tuvo lugar hasta mediados del siglo xx. En esta época, la base social de la ciudad se había diversificado lo suficiente como para fomentar el surgimiento de maestros endémicos que fungieran como promotores culturales. Algunos de ellos eran de extracción indígena y otros no, pero de igual forma tuvieron gran incidencia en la vida social y política de la Sierra. Sus conocimientos profesionales y su pertenencia a un gremio, que cada vez iba cobrando mayor fuerza como corporación a nivel nacional, los dotaron de un capital cultural y simbólico que les daba poder y legitimidad en el interior de su entorno local. Por su posición privilegiada y su instrucción se fueron conformando como críticos, tanto de los políticos locales como de los caciques y los hacendados que cometían injusticias en la zona.

El recorrido de la bandera Siera es un ejemplo, entre varios, de manifestaciones culturales que muestran el interés de una parte de la población -en este caso, en su mayoría, maestros normalistas- por reivindicar su pasado y reelaborar una identidad cultural. Como parte de las acciones por rescatar la participación de Zongolica en la gesta independentista, además del ritual antes descrito, existen algunos otros elementos que refuerzan el culto a la bandera. Uno de estos es el himno a la bandera Siera que fue compuesto por el profesor y músico zongoliqueño Heladio J. Celis Lara. Las estrofas de esta pieza musical describen el lábaro y las hazañas del ejército, en especial las del cura Juan Moctezuma, y dan realce a su importancia en la historia nacional:

Zongolica también está presente en la historia vital de esta nación, y la sangre derramada de su gente 
que regaron por la patria y pabellón. ${ }^{6}$

Esta pieza está presente en los actos cívicos en los que aparece la bandera y es ejecutada en las escuelas de la región.

La casa-museo del profesor Amadeo Méndez es otro ejemplo material de este interés de los maestros por rescatar y resignificar su pasado. En la primavera del 2010, me encontraba deambulando por la ciudad, en busca de información sobre la celebración de la bandera Siera. Varios de los pobladores con los que tuve contacto me indicaron que debía visitar al maestro Amadeo Méndez, por ser "un experto en el pasado de la ciudad y, además, porque en su casa albergaba un museo con piezas que podrían ser de mi interés". Me fue fácil llegar a la casa, ya que se encuentra en el primer plano de la ciudad. Se trata de una agradable casa de mampostería, con un jardín trasero a manera de huerta. El maestro, como lo habían descrito sus vecinos, era un hombre que poseía un extenso conocimiento del pasado de la ciudad y una gran disposición para compartirlo.

Actualmente jubilado, el profesor inició su carrera magisterial en 1964, sin contar con la formación de maestro normalista, por lo que se desempeñó en comunidades rurales alejadas de la ciudad. Posteriormente, gracias a su empeño y a un programa de superación académica, logró completar su formación y trabajar como educador en las escuelas más reconocidas de la ciudad de Zongolica. Afirma que se siente muy orgulloso de su origen nahua y que esto motivó su interés por recuperar información y materiales referentes a la historia de Zongolica. Al haber reunido una cantidad de piezas que "merecían ser exhibidas", decidió montar un modesto museo con sus propios recursos. Acondicionó la sala de su vivienda

${ }^{6} \mathrm{http}: / /$ cronicas.ugmex.edu.mx/index.php/cultura/104-bandera-sierra 
para este fin y durante mucho tiempo la tuvo abierta a quien quisiera conocer la historia de la ciudad. Comenta que algunos de los visitantes frecuentes fueron los alumnos de las escuelas de la región. Recientemente, delincuentes intentaron robar algunas de las piezas exhibidas y el profesor decidió cerrarlo, para abrirlo únicamente cuando "alguien se interesara realmente”. En este museo se encuentran vestigios prehispánicos, textos antiguos y otros objetos relacionados con la historia más reciente de la comunidad. Entre estos objetos se encuentra una reproducción de la bandera Siera, que el mismo maestro mandó bordar y que ha sido retratada por algunos de los cronistas e historiadores locales. 7

El profesor Méndez fue partícipe de los inicios de la ceremonia de la bandera Siera. En 1989, él era uno de los maestros que formaban parte de la Casa de la Cultura y que decidieron realizar un recorrido - una cabalgatapara conmemorar el episodio independentista en el que participó Zongolica. $\mathrm{Al}$ rememorar el devenir histórico que ha tenido la ceremonia desde su inicio, el maestro reflexiona en cuanto a las transformaciones que ha sufrido en los últimos años, y afirma que el ritual "perdió la esencia de lo que se hizo en un principio, el giro cambió más político que cívico". Considera que un ejemplo de este cambio hacia lo político se evidencia en que, a la llegada del PAN a la Sierra, el ritual se dividió, produciendo una disputa entre los grupos por el espacio donde debía llevarse a cabo la celebración. Así, la presencia del nuevo grupo político generó iniciativas por organizar dos recorridos diferentes para conmemorar la participación de Zongolica en la guerra de independencia. ${ }^{8}$

7 Información basada en dos entrevistas realizadas al profesor Amadeo Méndez en abril de 2010 y en marzo de 2016.

${ }^{8} \mathrm{La}$ reflexión del profesor Amadeo se refiere a acontecimientos que tuvieron lugar después de 2010. 
Otro maestro normalista que ha contribuido con su obra a la elaboración de una identidad cultural resignificada para su pueblo es el profesor Honorio Contreras Pavia, quien se desempeñó como orador en el recorrido de la bandera en 2010. El maestro Honorio es autor de textos sobre la historia de Zongolica, especialmente sobre el desarrollo del sistema educativo en la región (1993). En 2010 se encontraba trabajando en un documento sobre la historia de la bandera Siera. Los discursos que ofreció durante el recorrido de la bandera rememoraban la llegada de los nonoalcatzoncoliuque a la región, enfatizando el carácter valiente y guerrero de estos viajeros procedentes del Altiplano. En su charla se evidenciaban conocimientos sobre la historia de Zongolica, especialmente la anterior a la llegada de los españoles, adquiridos de mucho tiempo atrás y reforzados por la consulta de textos especializados.

Durante la conversación que mantuve con el maestro Contreras, conocí a un grupo de amigos suyos, también profesores, con interés por la historia de Zongolica. Algunos de ellos también habían contribuido al fortalecimiento de la historia de su pueblo, pues su interés por esta había quedado asentado en textos y en poemas. El profesor Contreras es maestro normalista de carrera; su trayectoria le ha valido que una de las escuelas de enseñanza media lleve su nombre. En 2010, ejercía el cargo de cronista de la ciudad y era reconocido por sus publicaciones y por su conocimiento de la historia local.

Los maestros que hemos identificado con influencia en la cultura local -plasmada en publicaciones, en la creación de espacios culturales o de celebraciones- nacieron alrededor de los años cincuenta. Se formaron dentro de una política cultural que promovía el nacionalismo, en la forma de una exaltación de los símbolos nacionales. En estos años, su formación incluía una admiración por el pasado prehispánico, especialmente el de las 
culturas azteca y maya, pese a que al indígena actual se le veía como un elemento en proceso de aculturación, al que había que educar y abstraer de su mundo de ignorancia y de pobreza. Una de las tareas prioritarias asignadas a los maestros de esta época fue la creación de "ciudadanos mexicanos" a través de un acercamiento a los símbolos patrios (Gutiérrez, 2012).

Los maestros de Zongolica, aunque no integran un grupo como tal ya que se presentan facciones antagónicas entre estos-, comparten su interés por su pasado, su historia y la problemática ecológica. Este grupo valora el legado mesoamericano, especialmente los vestigios prehispánicos, que consideran representan una continuidad con sus antepasados. Especialmente el profesor Amadeo tiene un auténtico interés por la búsqueda de materiales para reconstruir la historia de su ciudad y de la sierra de Zongolica en general.

Figura 3. Ensayo previo al recibimiento de la bandera Siera. Los Reyes, Veracruz.

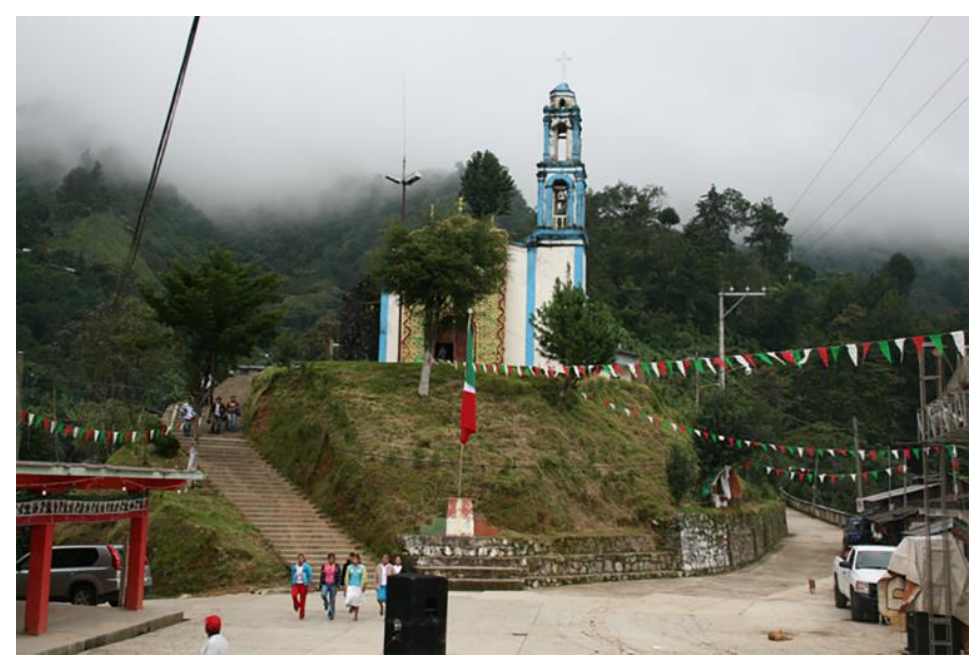

Foto: Claudia Morales Carbajal 
El tratamiento que recibió la bandera fue similar al que la población profesa a los santos. Esto significa que fue asumida como una entidad viva, susceptible de recibir ofrendas y de reaccionar ante este tipo de tratamientos. En la Sierra, igual que en otros pueblos indígenas mesoamericanos, se piensa que las imágenes tienen agencia y que poseen sentimientos y reacciones similares a las de los humanos.

Otra de las dimensiones simbólicas de este ritual es su vínculo con la religión católica. El ritual de la bandera Siera conserva uno de los elementos que definieron el nacionalismo de México desde su fundación como nación: la presencia de símbolos que representan a entidades religiosas católicas. En la etapa independentista se estableció una clara relación entre identidad, religión y Estado, la cual se materializa en el uso de imágenes religiosas como insignias (Lomnitz, 1993).

Este vínculo con la religión católica se manifestó en la última etapa del recorrido. La "peregrinación" de la bandera finalizó en la explanada de la iglesia de San Francisco, donde fue recibida con fuegos artificiales y discursos. El recibimiento volvió a reafirmar los fuertes lazos fundacionales que tuvieron la Iglesia y la Nación en los primeros años del nacimiento del México independiente. El cronista de la ciudad, el maestro Honorio Contreras, recuerda que, hasta hace unos años, el que recibía la bandera al llegar a Zongolica era el sacerdote, quien la rociaba con agua bendita y oficiaba una misa en su honor. En 2010, aunque no fue acogida por el sacerdote, la parroquia tuvo un papel central en los festejos.

La iglesia estuvo presente en todo momento en la celebración, ya que la casa parroquial fue acondicionada como un "museo" donde se exhibieron réplicas de la bandera, algunas de las monedas que se produjeron en la región durante este periodo, fotografías y otros objetos relacionados con el "Ejército de la Sierra". 


\section{Tradiciones selectivas, conmemoraciones y rituales}

Comúnmente el término 'ritual' es atribuido a los ámbitos relacionados con la esfera de lo sagrado, de las denominadas "sociedades tradicionales". Como argumenta Solange Alberro (1995: 187), a partir de la Ilustración se gestó una dicotomía cada vez mayor entre las formas del pensamiento laico y el religioso, concediéndole a la acción política un escenario diferenciado. No obstante, en el siglo XIX se dieron las bases para la creación de nuevas formas de ritualidades, emparentadas con la instrumentalización del poder y de sus símbolos, esta vez no como atributos de orden divino, sino como parte de los circuitos del poder mundano. La producción de rituales cívicos cobró, a partir del siglo XIX, un lugar de primer orden, para legitimar las nuevas formas del poder público y los nacientes Estados-nacionales modernos:

... la práctica propiamente política necesitó adoptar reglas y etiquetas para regir sus manifestaciones públicas, en particular las que tenían por función expresar un hecho o acontecimiento preciso y a la vez fijar en las mentes y los corazones las ideas e imágenes que afianzan un mensaje determinado. De ahí el recurso a "rituales" y "liturgias", inspirados en los sistemas religiosos como mecanismos apropiados para lograr estos propósitos (Alberro, 1995: 187-188).

Marc Abélès (1988: 391), siguiendo a Jürgen Habermas (1986: 241), llama la atención sobre la manera en cómo las "técnicas de demostración y organización" ocuparon un lugar privilegiado en la "constitución del orden público", dentro de las denominadas sociedades modernas. Representar lo político en la sociedad moderna exigía la producción de actos y de dramas, de técnicas de demostración, que pusieran de manifiesto el ejercicio del 
poder. Así, los desfiles y los actos conmemorativos, más allá de ser actos del pasado, ejercen un efecto presente y una relectura de los símbolos y de sus formas de constitución. Producen legitimidad y abren un diálogo permanente de los grupos con su pasado y con el lugar que ocupan en la esfera pública.

En esta dirección, Raymond Williams (1980) propuso el término de "tradición selectiva" como una noción conceptual para pensar la producción de instituciones y de formaciones. Williams rechazó la definición de las tradiciones como segmentos históricos inertes o rastros del pasado, meras supervivencias que llegan hasta nosotros. Las definió como formas poderosas de incorporación del pasado en el presente. Él considera la tradición selectiva como "una versión intencionalmente selectiva de un pasado configurativo y de un presente preconfigurado, que resulta entonces poderosamente operativo dentro del proceso de definición e identificación cultural y social" (1980: 137), y agrega: "Es una versión del pasado que se pretende conectar con el presente y ratificar. En la práctica, lo que ofrece la tradición es un sentido de predispuesta continuidad" (1980: 138). Así, pues, la noción de "tradición selectiva" permite contextualizar las formas de recuperación de la memoria, sus políticas y, sobre todo, la constitución de hegemonías, entendidas estas como construcciones vívidas de significados y de valores (1980: 131).

En este contexto, los rituales y las narrativas cívico-morales constituyen una plataforma ideológica de primer orden en la construcción de los Estados-nacionales. Estas narrativas hacen de la educación cívica un instrumento central para difundir patrones comunes de identidad mediante la ritualización de prácticas conmemorativas tales como los días de la bandera o de la patria (Casas, 2008: 104). Los actos conmemorativos recuperan y condensan significados centrales en la memoria grupal; 
seleccionan en la tradición puntos medulares que dan especial sentido a la vida e identidad a los individuos que comparten un grupo (Calderón, 2006; Díaz, 2011; Quezada, 2009; entre otros). Son un motor fundamental en la construcción de hegemonía.

Sin embargo, existe también, por otra parte, toda una bibliografía referente al papel performático y de contienda que tienen los rituales y los actos conmemorativos (Autry, 2013; Dejung, 2007; Tumarkin, 1987; etc.). Los rituales y las tradiciones aparecen como lugares activos de (re)producción cultural, no como figuras fijas en la producción de la historia. Se encuentran sujetos a los campos políticos y a las formas de resistencia. John y Jean Comaroff (1993), quienes han analizado eventos rituales en sociedades sometidas a regímenes coloniales, están de acuerdo en considerar, de manera prioritaria, el pasado de dominación de los pueblos y su historia particular, en el que la política y la identidad son elementos clave e inseparables:

... For by demystifying and detaching it from the sacred, they allow the possibility that ritual may be creative, constitutive practice -and, hence, an instrument of history in all human societies at all times. Rather than being reduced to a species of ceremonial action that insulates enchanted, selfreproducing Systems from the "real" World, then, ritual may be seen for what it often is: a vital element in the processes that make and remake social facts and collective identities (Comaroff y Comaroff, 1993: xvi).

En el caso de la bandera Siera, es posible observar la contienda entre actores regionales por relacionarse con el "capital cultural" que representa el ritual. La ceremonia fue concebida como un elemento que contribuiría a reafirmar la identidad del pueblo de Zongolica como forjador del movimiento de independencia nacional. Esto permite reposicionar la historia regional 
dentro del marco mayor de la historia nacional. El sentido de la ceremonia subraya que la Sierra no tuvo un papel pasivo dentro del movimiento, sino que sus acciones coadyuvaron al triunfo independentista y, además, convirtieron a los zongoliqueños en creadores de símbolos compartidos.

Esta identidad, reelaborada por los intelectuales locales, adquirió su carácter de patrimonio cultural al ser colocada en los espacios "oficiales" por los políticos del lugar. Estos últimos dejaron en manos de los intelectuales la reproducción y la reactualización del sentido histórico y de identidad que el ritual tuvo originalmente y, a cambio de esto, tomaron en sus manos la organización y el diseño de este, incluyendo de manera central su participación. Este juego performativo les permite reafirmar su presencia y construir una imagen política hacia el exterior, recibiendo las muestras de respeto que se otorgan a la bandera como si fueran hacia sus personas.

El evento cobra especial importancia a nivel regional porque coincide con el tiempo de la restitución de las tierras a los pueblos de la Sierra, mismas que habían sido objeto de más de dos siglos de litigios. La restitución de tierras a los pueblos fue, en su momento, mucho más significativa para la región que la independencia lograda ante el imperio español. Por esto la Independencia tiene un doble significado para los serranos: es un evento nacional y a la vez señala un triunfo regional, que conllevó la recuperación de su libertad a través de volver a obtener sus tierras.

\section{Reflexiones finales}

El ritual de la bandera Siera puede ser incluido como un fenómeno de tradición selectiva, en la que se intenta establecer un vínculo con un evento que ocurrió en 1810. Debemos mencionar que los pobladores se han visto 
envueltos en diferentes movimientos y eventos, incluidos la Revolución mexicana, su resistencia ante la usurpación de tierras por parte de los españoles durante la Colonia y un sinnúmero de lances significativos. Sin embargo, entre todos estos, eligieron conmemorar este episodio independentista.

El ritual de la bandera Siera fue originado en el seno de la élite intelectual de la ciudad de Zongolica con los propósitos de recrear su identidad como pueblo libre y de resaltar su participación en el nacimiento de México como nación independiente. Posteriormente, este ritual fue retomado por el ayuntamiento de la ciudad, quien lo patrocina y lo promueve. Al incluirse las autoridades, quienes se apropiaron de la organización y de la presentación del ritual, inició un juego de negociación política. La participación de los agentes oficiales dio a la ceremonia y a su historia un marco regional de difusión. A cambio, los políticos locales reclaman su intervención activa en la celebración, promoviendo con esto su imagen personal, la cual, en un juego de performance, recibe los honores otorgados a la bandera.

La bandera Siera es un símbolo que encarna a la Sierra de Zongolica y significa al pueblo nahua. El ritual nos remite a una relectura de la identidad étnica de la Sierra a través de posicionarla como elemento activo en la lucha independentista, dejando de lado su imagen de región oprimida y marginal. Al igual que ocurría con los discursos del nacionalismo decimonónico, prevalece la exaltación de los míticos nahuas fundadores, de la Sierra. Y los actuales grupos indígenas son excluidos de la arenga.

En los últimos 20 años, en la sierra de Zongolica se han presentado diferentes muestras de resignificación identitaria en las que participan maestros y políticos locales. Algunos de estos brotes están relacionados con la reactivación de elementos culturales como el Xochitlali, que se realiza el 
primer viernes de marzo; otros, con la recreación de "bodas tradicionales" para su transmisión televisiva; otros más, con la creación de música local y el rescate de la lengua náhuatl (Morales, 2014). ${ }^{9}$ En la mayoría de estas acciones, al igual que ocurre en el ritual de la bandera Siera, es posible identificar la mano hegemónica del Estado a través de políticas públicas de reactivación y de difusión cultural o de un proceso de formación de una ideología nacionalista a través de la escuela, como ocurre con el ritual que nos ocupa. Sin embargo, también es posible reconocer la agencia de los actores sociales y las motivaciones personales que los llevan a elaborar una identidad autónoma. Así, la ceremonia de la bandera Siera es un ejemplo de cómo se construye y se negocia la memoria histórica y cultural en el siglo veintiuno.

\section{Referencias}

ABÉLÈS, Marc (1988). "Modern Political Ritual: Ethnography of an Inauguration and Pilgrimage by President Mitterand", Current Anthropology. Vol. 29, núm. 3, junio, pp. 391-404.

ALBERRO, Solange (1995). "Rituales cívicos", Historia mexicana. Vol. XLV, núm. 2, pp. 187-189.

ÁlVAREZ SANTIAGO, Héctor (1991). El Xochitlalli en San Andrés Mixtla. Ritual e intercambio ecológico entre los nahuas de Zongolica. México: Gobierno del Estado de Veracruz.

ARIZPE, Lourdes (2011). "Introducción”, El patrimonio cultural cívico. La memoria política como capital social. México: UNAM/Porrúa.

\footnotetext{
9 https://www.youtube.com/watch?v=a3BRw-kZegI
} 
AUTRY, Robyn (2013). "The Political Economy of Memory: The Challenges of Representing National Conflict at 'Identity-Driven' Museums”, Theory and Society. Vol. 42, núm. 1, pp. 57-80.

BAUR ARENAS, Carolina (2010). México a través de sus hombres y banderas. México: Plaza y Valdés.

CALDERÓN MÓLGORA, Marco A. (2006). "Festivales cívicos y educación rural en México", Relaciones. Vol. XXVII, núm. 106.

CASAS MENDOZA, Carlos Alberto (2008). "Región, fronteras interiores y estado. Una aproximación comparativa a partir de dos casos latinoamericanos", Ana Irisarri Aguirre, Alexander Betancourt y M. Nicolás (coords.), Estudios regionales y de fronteras interiores. México: Porrúa, pp. 103-122.

CASAS MENDOZA, Carlos Alberto (2016). "Rituales públicos y conmemoraciones en el Sesquicentenario de la Independencia brasileña”, Alexander Betancourt (ed.), Escritura de la historia y política. El Sesquicentenario de la Independencia en América Latina. Lima: Instituto Francés de Estudios Andinos, pp. 61-96.

COMAROFF, John, y Jean Comaroff (1993). Modernity and its Malcontents. Chicago: Universidad de Chicago.

CONTRERAS PAVIA, Honorio (1993). La educación en Zongolica (mecanografiado). Zongolica, Veracruz.

CRUZ PAZOS, Patricia (2011). "Juan Moctezuma y Cortés: cacique, cura e insurgente (1754/57-1816)", Revista Española de Antropología Americana. Vol. 4, núm. 2, pp. 521-545.

DEJUNG, Christof (2007). "Dissonant Memories: National Identity, Political Power, and the Commemoration of World War Two in Switzerland”, Oral History. Vol. 35, núm. 2, pp. 57-66. 
DÍAZ ARIAS, David (2011). "Pequeños patriotas y ciudadanos: infancia, nación y conmemoración de la independencia en Costa Rica”, Araucaria. Vol. 13, núm. 25, pp. 86-107.

GLEDHILL, John (2000). El poder y sus disfraces. Perspectivas antropológicas de la política. Barcelona: Bellatera.

GUTIÉRREZ CHONG, Natividad (2012). Mitos nacionalistas e identidades étnicas. Los intelectuales indígenas y el estado mexicano. México: UNAM.

GUZMÁN I ROMERO, Melitón (1968). El ex Cantón de Zongolica. México: Citlatépetl.

HABERMAS, Jürgen. (1986 [1962]). L'espace public. París: Payot.

LOMNITZ-ADLER, Claudio (1993). "Antropología de la nacionalidad mexicana”, Lourdes Arizpe (coord.), Antropología Breve de México. México: UNAM, pp. 35-71.

LOMNITZ-ADLER, Claudio (1995). Las salidas del laberinto. Cultura e ideología en el espacio nacional mexicano. México: Joaquín Mortíz/Planeta.

MORALES CARBAJAL, Claudia (2014). Las voces de la montaña: diálogos a través del ritual entre los nahuas de Zongolica, Veracruz. Tesis de doctorado, UNAM-IIA.

ORTIZ ESCAMILLA, Juan (1997). Veracruz en armas. La guerra civil 1810-1820. Antología de documentos. Vol. 1. México: Universidad Veracruzana/Secretaría de Educación de Veracruz/Gobierno del Estado de Veracruz.

PROGRAMA DE LAS NACIONES UNIDAS PARA EL DESARROLLO (2010). Informe sobre Desarrollo Humano de los Pueblos Indígenas en México. México: PNUD. 
QUEZADA O., Margarita de J. (2009). "Las ceremonias cívicas escolares como ritos identitarios", Revista Latinoamericana de Estudios Educativos. Vol. 39, núms. 1 y 2, pp. 193-233.

RAPPAPORT, Joanne (1990). The Politics of Memory. Native Historical Interpretation in the Colombian Andes. Cambridge: Cambridge University Press.

ROMERO, Raúl R. (2001). Debating the Past. Music, Memory, and Identity in the Andes. Oxford: Oxford University Press.

SÁNCHEZ DE ANDA, Guillermo (1990). "Zongolica, bandera y monedas”, Rafael Arriola Molina, José Corona Núñez y Ricardo Méndez López (eds.), Los símbolos patrios. Xalapa: SEP, pp. 43-56.

SEFIPLAN (2019), Cuadernillos Municipales. México: Gobierno del Estado de Veracruz, $\quad$ http://ceieg.veracruz.gob.mx/wpcontent/uploads/sites/21/2016/o5/Zongolica.pdf

TURMAKIN, Nina (1987). "Myth and Memory in Soviet Society", Culture and Society. Septiembre-octubre, pp. 69-72.

WILLIAMS, Raymond (1980). Marxismo y literatura. Barcelona: Península. 